\title{
Identifying the Effect of Product Types in the Relationships Between Product Discounts and Consumer Distrust levels in China's Online Social Commerce Market at the Era of Big Data
}

\author{
Lin $\mathrm{Li}^{1}$, Cheul Rhee ${ }^{2}$ and Junghoon Moon $^{3}$ \\ ${ }^{1}$ Department of Management, Kyung Hee University \\ 26 Kyungheedae-ro, Dongdaeimon-gu, South Korea \\ [e-mail: lilin@khu.ac.kr] \\ ${ }^{2}$ Department of e-Business, Ajou University \\ San 5 Wonchun-dong Yeongtong-gu 443-749, South Korea \\ [e-mail: crhee@ajou.ac.kr] \\ ${ }^{3}$ Program in Regional Information, Seoul National University \\ Gwanak-gu, Seoul 151-742, South Korea \\ [e-mail: moonj@snu.ac.kr] \\ *Corresponding author: Cheul Rhee
}

Received September 28, 2017; revised December 4, 2017; accepted Jaunuary 3, 2018; published May 31, 2018

\begin{abstract}
In the era of big data, consumers capture more and more economic surplus yet the seed of distrust also grows with the fast-spreading of social commerce, this paper began with the idea that product types may determine the degree of consumers' distrust even when identical discounts are offered for those products on Chinese social commerce websites. We also attempted to determine if distrust negatively affected consumers' purchase attitudes. 20 representative products that are commonly sold on social commerce websites in China were chosen to examine the relationships among product types, discount rates, distrust levels, and purchase attitudes. Inductive interview was used to collect the data as well as consumers' perceptions of the relationships. Data analysis results suggested that consumers like deep discounts, but their distrust levels increase along with the discount rates, however, the levels of increasing distrust vary according to product types. High, medium, and low discount rate categorizations were made and three propositions were suggested. This paper will contribute to the body of knowledge on online social commerce market and provide valuable implications for e-retailers and general consumers in online social commerce websites in China.
\end{abstract}

Keywords: Product discounts, consumer distrust, product types, purchase attitudes, social commerce 


\section{Introduction}

China's e-commerce market has unique characteristics that distinguishes itself from the e-commerce markets of other countries. Except for the well-acknowledged fact that China's e-commerce market is boosted by its huge population and grows at an extraordinary speed, there are several negative characteristics that cannot be ignored as well, such as the prevalence of fake products, frauds and deception. It is surveyed by China Online Shopping Market Research Center that approximately $25 \%$ of online consumers have obtained fake products [1], which is disproportionately higher compared to other major countries in the world and also raise the distrust issue among consumers. By a detailed examination of such a huge, special, and extreme Chinse market, more insights may be drawn and more contribution can be made to the academia as well as industry than other countries.

This paper focuses on the social commerce market among other e-commerce models in China due to the following reasons. Practically, with the development of Web 2.0, e-commerce is undergoing an evolution that enhances individuals' participations through social media and social networks [2]. Moreover, in the Industry 4.0 era, the ability to meet consumers' needs by providing customized products with the connection to social network is highly needed [3]. It is commonly believed that when a commodity price is discounted, consumers are more likely to like the commodity, and the bigger the discount rate is, the higher probability that consumers are going to like it. On the other hand, the larger the discount is, the higher level the distrust is. In other online commerce platforms, it is comparatively easier for consumers to have a rough guess or assumption of the costs based on their judgements and experience, and can decide which product is authentic and which is fake based on the discount rate of the product. However, it would be difficult to set the limit upon discount rate on social commerce websites, just like the Ticket Monster website in South Korea case. The reason is that many companies and restaurants use social commerce websites as platforms for promotions or advertisements, which makes consumers confused about what should be the limits of the discount rates that they can trust the products.

In other words, generally, the lower the price is, the higher probability that consumers like a product, but the distrust level also gets higher along the process. But The question also rises that would the distrust differs among different kinds of products? Based on the market observation, even if the same discount rate is applied to several products, some products may be purchased while others don't; and in the case of products and services, the preference and the purchase attitude may vary even if the same discount rate is offered. In the perspective of this research, the characteristics and types of products are considered as the main reason that causes the difference in different purchase attitudes.

The research question of this paper is "will the relationships between discount rates and distrusts change based on product types?", and it is believed by this paper that the clarification of the relationships between product types, distrust levels, discount rates and purchase intentions are a major contribution of this research. Even though there are many extant researches focusing on the studies of product type (e.g. [4], [5]), such as convenient goods, shopping goods and convenience goods, or high-involvement and low-involvement goods, but the product type classification methods do not help to solve the research question that this paper proposed. Also previous researchers on the analysis of the problem were limited to simply using traditional business theories as well [6]. As a result, instead of beginning with sorting out the product types, this research started with extracting 20 most popular items in 
social commerce websites in China, and to determine the price discount rate, distrust and purchase intention of each product. Through this backward, inductive method, this research hopes to find the product type classification that suits the limited setting of this research. That is to say, the research purpose of this paper is to find the product characteristics that cause the difference in the different distrust levels, since the tradtional product type classification methods cannot explain the distrust differences that occurred in Chinese social commerce scenario.

The reason to choose Chinese social market to study is for the purpose of controlling the cultural contingent effect that might be salient if multiple countries are chosen to study, thus, this study focused on Chinese social commerce market in particular. And inductive interview was used as research method since there is no existing theory to support empirical research even though this research has an intention to.

To the best of our knowledge, this study is one of the first attempts to investigate how product types influence the relationships between discount rates and distrust levels in the contexts of social commerce in China. Practically, this paper intends to provide social commerce retailers and practitioners regarding how to better set price strategies based on various product types.

\section{Literature Review}

\subsection{Social Commerce in China}

E-commerce is one of China's most successful business models and it is expected to cement its position as the world biggest online e-commerce market by 2020 [7]. It can be exemplified by the Double 11 shopping spree of China, 25.35 billion USD worth of products were sold in 24 hours on November 11, 2017 [8]. Among various kinds of e-commerce models, social commerce is one of the leading new trends that thrives in China. Social commerce is a new form of e-commerce that combines social media, such as SNSs to offer consumers the daily deals from local establishments [9]. Social commerce is also claimed to use many social technologies to improve online customers' shopping experiences [10]. Compared to other forms of e-commerce, social commerce provides substantial discounts, sometimes more than $50 \%$ for different kinds of products and services.

The social commerce boom in China is largely contributed to the rise of social media, such as Wechat, which is leading a new era of social sharing shopping experience. But if look beneath the glamorous surface of Chinese social commerce market, the problems start to reveal. Due to the low entry barriers, social commerce websites let new e-retailers get online quickly and easily [11]. The low set-up cost on one hand increases the effectiveness and reduces the products and services cost, but on the other hand, causes many problems as well, such as fake products, fraud, poor customer service, misleading information. Many customers have experienced negative shopping experiences on social commerce websites and grow distrust towards them.

Even though social commerce has been studied by previous research, such as the categorization of social commerce [12]; framework and elements analysis of social commerce [13]; and social commerce design guidance [14]. Chinese social commerce market is under insufficient study. Even though fixed-price group-buying has been studied on the top group-buying website in China [15], social commerce infrastructure and strategy is the research focus for most of the extant studies [16]. This research focuses on how the product 
types influence the relationships between discount rates and distrust levels, which has rarely been studied by previous researches.

\subsection{Distrust and Consumers' Purchase Attitudes in Social Commerce Market}

Even though the function of social commerce that enables customer reviews, recommendations and references to friends makes it popular among the past few years, the distrust issue arises as well due to the low entry cost of social commerce websites and the immaturity of the market. Many consumers have become the victims of malicious social commerce activities, such as fake products, exaggerated advertisements, deception, which practically cause the distrust among a growing number of online customers.

However, little research has investigated distrust in the contexts of social commerce, especially in Chinese case. Social commerce is a relatively new form of e-commerce, but it is gaining momentum and a comprehensive understanding of the distrust issue and how it shapes consumers purchase attitudes is highly needed. In addition, it is claimed by extant researches that consumers are prone to trust e-commerce websites more than social commerce websites [17]. Thus, the distrust issue of social commerce needs to be tackled with a profound practical reason.

As to the purchase attitude, from the retailers' perspective, it is argued by extant researches that the distrust issue on the social commerce platform influences consumers' purchase attitudes negatively and consequently many social commerce sellers cannot fully exploit the economic potential [18]. From the consumers' perspective, more than $70 \%$ of consumers depend on social media to make purchase decisions, and $40 \%$ of them share their reviews on social media after purchase products or services [19]. This research believes that the peer communication has dramatically changed how consumers' purchase attitudes are formed and if distrust emerges as a problem, it can tremendously impair the purchase attitude and result in the wrong purchase action or misleading information about purchase, and cause financial lost to individuals.

\subsection{Discount Rates and Social Commerce in China}

Social commerce websites in China provide various kinds of products and services, such as food and drink, travel products, performance tickets and health or fitness products, and many of them provide heavy discounts. Consumers usually buy the products and services and then share their ideas or experiences and product information through SNS, such as Facebook and Twitter (in China's case, Wechat) to help promote or complain about the products and services that they have bought [20]. In other words, consumers help to facilitate the promotion of the products and services that the sellers want to sell, thus, consumers play a more vital role in social commerce as agents for advertisements, either positive or negative, and this is one of the major differences that distinguish social commerce from e-commerce. Accordingly, many social commerce sellers offer heavy discounts, such as more than $50 \%$ to attract consumers for a good reputation in Chinese market.

It is well acknowledged that a company with a high reputation usually gets high level of customers' trust since a consumer-well-accepted reputation serves as an intangible asset that enhances trust [21] [22]. A good reputation is considered as an important factor for many social commerce retailers or companies since many of them are star-up companies, and they need a good reputation to strengthen their market power and be profitable in the highly competitive market environment in China. As a result, many social commerce retailers in 
China offer heavy discounts for promotion as a method to build their reputation and win consumers' trust.

However, based on the market observation, this paper found out that consumers sometimes get confused about which product they can trust and which they cannot since the cost of the product, which is their commonly used tool is not working well in the case of social commerce websites, due to the heavy discounts that many social commerce retailers offer as promotions or advertisements. Especially, even in the case of the same price discount, some products are chosen and some are not, or some services are chosen while some products are not. Therefore, this paper focuses specifically on whether this phenomenon is related to the product type, which cannot be explained by previous product classification methodologies in Chinese social commerce case.

\section{Research Methodology}

Research methodology adopted by this qualitative study is inductive interview, due to lack of existing theory to support empirical study. The inductive interview was employed to collect data of the distrust increasing points of the 20 chosen products of this research, and the reasons for the various distrust levels were extracted as well.

\subsection{Development of Data Collection Instrument}

As to the interview design, the research purpose of the interview is to find out how various types of products change the relationship between discount rates and distrust levels. For generalization of the research results, the interview page excluded all the design elements, but the participants were well aware that the items had been chosen from social commerce websites. 20 products were included for that they were among the best selling products in Chinese online social commerce websites, which are: paper, durian, staples, blueberries, gasoline, steak, travel package, TV stand, franchised buffet, movie ticket, car washing, investment golden bar, yoga mattress, gym exercise coupon, franchised business hotel room, shoes, strawberry picking, ice-cream, picture taking and foot massage. These products are very easy to be understood by interviewees without much extra descriptions, and also are related to their experience of shopping on social commerce websites. These products are believed to be chosen with solid practical reasons.

A face-to-face interview protocol was designed to collect data on interviewees' responses. The questions in the interview protocol are categorized into two types. They are: "At discount rate, you start to have distrust towards the quality of the product?"; "What are the reasons that you perceive each product differently and would you like to share with me?" (see Appendix 1). The first question is designed to collect information about the distrust increasing points for different types of products, and the second question is developed to find out the reasons for the various distrust levels. If the discount rates vary dramatically among the chosen products, this study is believed to provide evidence for validating the research framework, shown at Fig. 1, for a larger and empirical study [23]. 


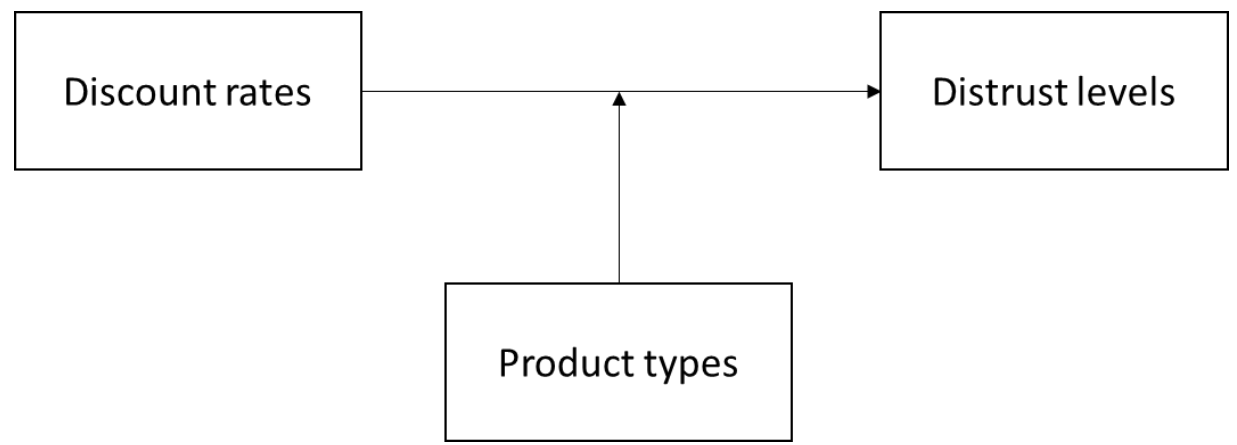

Fig. 1. Research framework on the effect of product types on relationship between discount rates and distrust levels

During each interview session, the interview started with the greeting, brief introduction of the research and received permission to continue the main part of the interview questions. Then, the two main research questions, "At___ (\%) discount rate, you start to have distrust towards the quality of the product?"; "What are the reasons that you perceive each product differently and would you like to share with me?", were asked for the 20 chosen experiment products, and the interview time varied from 20 minutes to 40 minutes due to individual differences. The face-to-face interview was employed in this research for a better and interactive communication.

\subsection{Data Collection and Data Analysis Method}

Seventy face-to-face inductive interviews were conducted among Chinese individuals aging from 18 to 30 years old, who are the main shopping force of social commerce websites in China, thus make them the research subject. Participants were from various cities in China, mainly from Beijing, Shanghai and Guangzhou, these cities are metropolis of China, and these cities have the most alive social commerce website purchase power and the participants are better aware of the contents of social commerce, thus they participated the interview with less difficulties to understand and proceed.

With the agreement of the participants, the interview contents were tape recorded, also notes were taken during the process of interview. During the data analysis process, the notes and the interview tape contents were compared for cross validation [24].

Inductive data analysis techniques were employed for interview data analysis. The process is described as data reduction, data display, and conclusion making and verification [25]. The coding process was developed through the constant comparative method [26] in order to find codes and make categories for distrust reasons. First, the interview data was analyzed based on chucks of contents, or conceptual unites and also provided with codes, which is similar to key words. For example, one of the interviewee answered for the reason for her answer to paper as followed:

Honestly, I usually buy a lot of paper once I see a more than $60 \%$ discount on the social commerce website. These products don't have much difference when I use them. Even though some paper might be thicker and some thinner, I don't mind much about the quality. (Interviewee 15, Female age 25)

Through the analysis of her interview contents, her reasons for low distrust level towards paper can be categorized as "homogeneity" since she did not find the quality of paper varies 
much, thus the code of her content was "not much difference in quality". Other data was also coded like this for the categorization of the distrust reasons.

\section{Data Analysis Results}

The discount rates, the reasons for distrust, the combination of discount rates and reasons for distrust, and product categorization are shown in this part.

The relationship between product types, discount and distrust level is shown in Table 1. It can be interpreted that the distrust level can be grouped as low, medium and high groups based on the distrust increasing point of each product. Movie ticket, staples, and paper were found out to be low in distrust level; while investment golden bar and gasoline were considered to be in high distrust level group. The rest 15 products were treated as medium by the interviewees about the distrust level.

Table 1. Relationships between product types, distrust level and distrust increasing point

\begin{tabular}{|c|c|c|}
\hline Distrust level & Product & $\begin{array}{l}\text { Distrust increasing point } \\
\text { ( }>\text { ?\% discount) }\end{array}$ \\
\hline \multirow{3}{*}{ Low } & Movie ticket & $>80 \%$ \\
\hline & Staples & $>75 \%$ \\
\hline & Paper & $>70 \%$ \\
\hline \multirow{15}{*}{ Medium } & Yoga mattress & $>65 \%$ \\
\hline & Ice-cream & $>60 \%$ \\
\hline & Foot massage & $>55 \%$ \\
\hline & TV stand & $>50 \%$ \\
\hline & Strawberry picking experience & $>50 \%$ \\
\hline & Car washing service & $>45 \%$ \\
\hline & Durian & $>45 \%$ \\
\hline & Blueberries & $>45 \%$ \\
\hline & Shoes & $>40 \%$ \\
\hline & Franchised buffet & $>40 \%$ \\
\hline & Gym exercise coupon & $>40 \%$ \\
\hline & Travel package & $>40 \%$ \\
\hline & Picture taking & $>35 \%$ \\
\hline & Steak & $>35 \%$ \\
\hline & Franchised business hotel room & $>30 \%$ \\
\hline \multirow{2}{*}{ High } & Investment golden bar & $>25 \%$ \\
\hline & Gasoline & $>20 \%$ \\
\hline
\end{tabular}

Fig. 2. shows an inner logic of this paper, for the low distrust group, individuals distrust increasing points are relatively very high in numbers, such as $70 \%$; for the high distrust group it is the opposite, meaning that participants start to have distrust of the products at very small discount amounts, such as $20 \%$. While the medium distrust group is in the middle, people distrust level start to increase around 30\%-50\%. 


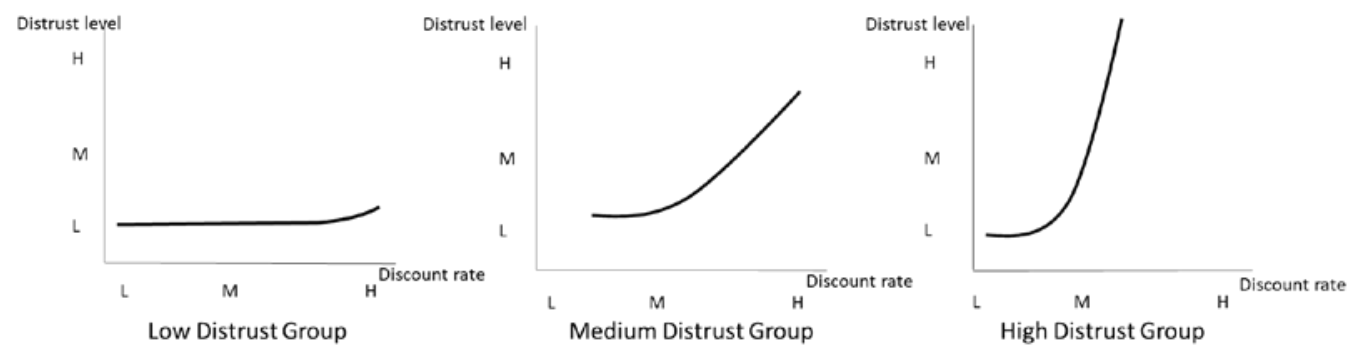

Fig. 2. Classification of distrust groups

By the coding of the various reasons extracted from seventy interview contents, each product can be summarized with one or two main reasons for distrust, which is shown in Table 2. To be specific, paper, durian, blueberries, steak and strawberry picking were categorized as perishable, paper, durian, staples, blueberries, steak, movie ticket and yoga mattress were categorized by participants as related to homogeneity or heterogeneity products. The quality for homogeneous products are not easy to distinguish by people, while heterogeneous products are the opposite, means people can easily tell the difference in product quality. Under the classification of past experience, there is car washing and gym exercise coupon. This means that people linked the quality of these two products more closely to their previous experience of using it, so it provides a benchmark for their decisions later. Paper, staples, gasoline, investment golden bar were considered related to cost of raw material for the distrust reasons. TV stand, franchised buffet, yoga mattress, franchised business hotel room, shoes and ice-cream were linked to brand effect for their distrust reasons. Under the category of information transparency, the products are car washing, gym exercise coupon, picture taking and foot massage, means that people feel with the easy access of information on social commerce websites, the price of these kinds of services can be easily compared with a low search cost. Last, travel package and gym exercise coupon were categorized into sensitivity (seasonality) group, means participants feel the price of these products are highly related to different seasons.

Table 2. Summary of distrust reasons

\begin{tabular}{|c|c|c|c|c|c|c|c|}
\hline Products & P & H & PE & CRM & BE & IT & S \\
\hline \hline Paper & & $\checkmark$ & & $\checkmark$ & & & \\
\hline Durian & $\checkmark$ & $\checkmark$ & & & & & \\
\hline Staples & & $\checkmark$ & & $\checkmark$ & & & \\
\hline Blueberries & $\checkmark$ & $\checkmark$ & & & & & \\
\hline Gasoline & & & & $\checkmark$ & & & \\
\hline Steak & $\checkmark$ & $\checkmark$ & & & & & \\
\hline Travel package & & & & & & & \\
\hline TV stand & & & & & $\checkmark$ & & \\
\hline Franchised buffet & & & & & $\checkmark$ & & \\
\hline Movie ticket & & $\checkmark$ & & & & & \\
\hline Car washing & & & $\checkmark$ & & & & \\
\hline IGB & & & & $\checkmark$ & & & \\
\hline Yoga mattress & & $\checkmark$ & & & $\checkmark$ & & \\
\hline GEC & & & $\checkmark$ & & & $\checkmark$ & \\
\hline FBHR & & & & & $\checkmark$ & & $\checkmark$ \\
\hline Shoes & & & & & $\checkmark$ & & \\
\hline Strawberry picking & $\checkmark$ & & & & & & \\
\hline Ice-cream & & & & & $\checkmark$ & & \\
\hline
\end{tabular}




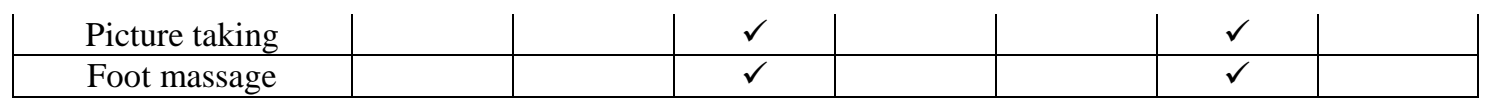

Note: IGB= Investment golden bar; GEC= Gym exercise coupon; FBHR= Franchised business hotel room;

$\mathrm{P}=$ Perishable; $\mathrm{H}=$ Homogeneity or Heterogeneity; $\mathrm{PE}=$ Past Experience; $\mathrm{CRM}=$ Cost of Raw Material; $\mathrm{BE}=$ Brand Effect; IT = Information Transparency; S=Sensitivity (Seasonality)

$\checkmark=$ Highly related

By integrating the discount rates and the distrust reasons, Table 3 is shown as combination of both of them, and the products types were categorized based on the distrust reasons. Also the codes mentioned by the interviewees and the frequency of the codes were demonstrated as well. To be specific, movie ticket, paper and staples were under the characteristic of homogeneity, means that participants considered these products as "same, not much difference in quality", so that the distrust levels did not increase until high discount numbers. While yoga mattress, ice cream, TV stand, shoes, and franchised buffet were regarded as the products effected by various brands. Foot massage, car washing, gym exercise coupon and picture taking were considered as effected by information transparency, which means that people nowadays can easily compare the quality of these products and services with the development of social commerce, thus, they thought similar services were offered for these products and services, so that their distrust increased at medium levels. Durian, blueberries and steak were categorized by the interviewees as the products that can easily go bad and each of them varied a lot in favor and quality, so these three products were categorized as perishable and heterogonous products. Travel package and franchised business hotel room were two products and services that considered as influenced by seasons a lot, such as more expensive in spring and summer, but get cheaper in winter, also the brand effect was mentioned as important by interviewees, so that their distrust increased at medium levels. Lastly, peoples' distrust towards investment golden bar and gasoline increased at small discount levels, such as $20 \%$ for that interviewees said these products have fixed cost so that if the price dropped a lot, they severely worried about the quality and do not believe that these products can have high discount rates.

Table 3. Categorization of product types based on distrust reasons

\begin{tabular}{|c|c|c|c|c|c|}
\hline $\begin{array}{l}\text { Distrust } \\
\text { level }\end{array}$ & $\begin{array}{c}\text { Product } \\
\text { Characteristics }\end{array}$ & Products & Code & $\begin{array}{c}\text { Times } \\
\text { mentioned by } \\
\text { interviewees }\end{array}$ & $\begin{array}{c}\text { Distrust } \\
\text { increasing } \\
\text { point }\end{array}$ \\
\hline \multirow{3}{*}{ Low } & \multirow{3}{*}{ homogeneity } & Movie ticket & \multirow{3}{*}{$\begin{array}{c}\text { Same, not much } \\
\text { difference in } \\
\text { quality }\end{array}$} & 42 & $80 \%$ \\
\hline & & Paper & & 25 & $70 \%$ \\
\hline & & Staples & & 40 & $75 \%$ \\
\hline \multirow{5}{*}{ Medium } & \multirow{5}{*}{ Brand Effect } & Yoga Mattress & \multirow{5}{*}{$\begin{array}{l}\text { Brand matters, } \\
\text { low quality } \\
\text { brand, high } \\
\text { quality brand }\end{array}$} & 32 & $65 \%$ \\
\hline & & Ice Cream & & 29 & $60 \%$ \\
\hline & & TV Stand & & 39 & $50 \%$ \\
\hline & & Shoes & & 27 & $40 \%$ \\
\hline & & FB & & 25 & $40 \%$ \\
\hline \multirow{4}{*}{ Medium } & \multirow{4}{*}{$\begin{array}{l}\text { Information } \\
\text { Transparency }\end{array}$} & Foot massage & \multirow{4}{*}{$\begin{array}{l}\text { Easy to compare } \\
\text { price, so many } \\
\text { offer similar } \\
\text { service }\end{array}$} & 22 & $55 \%$ \\
\hline & & Car washing & & 37 & $45 \%$ \\
\hline & & GEC & & 26 & $40 \%$ \\
\hline & & Picture taking & & 33 & $35 \%$ \\
\hline \multirow{3}{*}{ Medium } & \multirow{3}{*}{$\begin{array}{l}\text { Perishable } \\
\text { +Heterogeneity }\end{array}$} & Durian & \multirow{3}{*}{$\begin{array}{l}\text { Go bad so } \\
\text { quickly, difficult } \\
\text { to tell the quality }\end{array}$} & 50 & $45 \%$ \\
\hline & & Blueberries & & 46 & $45 \%$ \\
\hline & & Steak & & 42 & $35 \%$ \\
\hline
\end{tabular}




\begin{tabular}{|c|c|c|c|c|c|}
\hline \multirow{2}{*}{ Medium } & \multirow{2}{*}{$\begin{array}{l}\text { Brand Effect } \\
+ \text { Sensitivity } \\
\text { (Seasonality) } \\
\end{array}$} & Travelpackage & \multirow{2}{*}{$\begin{array}{l}\text { Different season } \\
\text { different price, } \\
\text { company brand }\end{array}$} & 30 & $40 \%$ \\
\hline & & FBHR & & 40 & $30 \%$ \\
\hline \multirow{2}{*}{ High } & \multirow{2}{*}{$\begin{array}{l}\text { High Cost of } \\
\text { Raw Material }\end{array}$} & IGB & \multirow{2}{*}{ The cost is fixed } & 38 & $25 \%$ \\
\hline & & Gasoline & & 45 & $20 \%$ \\
\hline
\end{tabular}

Note: FB=Franchised buffet; GEC= Gym exercise coupon; FBHR= Franchised business hotel room; IGB= Investment golden bar.

\section{Conclusion and Discussion}

In conclusion, due to the special characteristics of Chinese e-commerce market and social commerce market, this paper focused on the Chinese social commerce market, and found out that the relationships between product discounts and distrust levels are influenced by product types, which is considered a key contribution of this research. Inductive interview methodology was employed and three propositions were made based on our main findings regarding various product types.

These three propositions are considered to be the theoretical, as well as practical contributes of this research paper. The theoretical implication of three propositions lie in the fact that due to lack of theoretical support, this paper conducted a qualitative research and the propositions are believed to provide guidance for further empirical study in the contexts of Chinese social commerce websites. The practical implication is that the social commerce merchants can get practical suggestions on how to set the discount rates so that the promotion goal is achieved without unexpectedly raise the distrust level of online consumers in the social commerce websites in China. The three propositions are elaborated as below.

Proposition 1: The low distrust level products were found to be related to homogeneous characteristics of products.

Homogeneous and heterogeneous product is an important product type that influenced consumers' distrust levels, and the distrust levels only increased after high discount rates are employed. If the product quality cannot be easily distinguished by consumers, people are prone to be insensitive to the discount rates, means only after high discount rates, such as $80 \%$, people start to grow distrust. And these products are regarded as homogeneous products.

Practically, it gives implications to the Chinese online social commerce sellers and e-marketers. For homogeneous products, it would be a preferable market choice to offer high discount rates to attract online consumers' attentions since peoples' distrust level increasing points are relatively high and insensitive to price changes due to the slight quality differences among these products. Such as the movie ticket, it is a reprehensive example that shows peoples' purchase attitudes towards homogeneous products, thus high discount rates can be used as an effective promotion tool without increasing consumers' distrust levels for most of the situations.

Advertising e-managers and website developers can also be enlightened from this proposition that for homogeneous products, it is a good strategy to put the deep-discounted homogeneous products at the obvious positions or the front page of the social commerce websites so that people can see these products easily and trust these products even after the deep discount rates are employed, so that the websites draw more attentions and build a good reputation among online consumers.

Proposition 2: The medium level distrust level is considered to be related to brand effect, information transparency, heterogeneous products/perishable, and seasonality.

To be specific, as to brand effect, it is considered as one of the main characteristic of products that online consumers consider when they see high discount rates on social 
commerce. However, it is quite challenging for social commerce marketers since high discount of famous or international brands usually difficult to acquire, and even they managed to achieve that, many consumers might question the quality of the products and worry about the "fake products", which is a rampant problem that happened in Chinese e-commerce market. On the other hand, if the discount rates are too less, the online social commerce do not have competitive advantages over Chinese e-commerce giant, such as Taobao.

Accordingly, it would be a more appreciate market strategy to set medium discount rates to get peoples' purchase intentions, and not raise the distrust level for the brand-sensitive products, such as the durable products that have been proved belong to this category in this research.

Heterogeneous products are on the contrary to homogeneous products, people are quite sensitive to the discount rates and start to have suspensions at small discount rates. For example, fruits are considered as representative heterogeneous products, and people might worry that if the heavy-discounted fruits have gone bad or have other quality problem so that they are sold at high discounts.

Practically, the heterogeneous products are not recommended to set high discount rates for promotion for advertising e-managers and e-marketers, since consumers might have doubts about the quality of the products if the discount rates are too high. Due to the high variation of the quality of heterogeneous products, people intend to consider highly discounted heterogeneous products as low quality, accordingly medium level discount rates might have more positive influence on consumers' purchase intentions as this paper advocated.

Information transparency became a noticeable product characteristic on Chinese social commerce website due to the fast development of Internet, since it increases the information endowment of the online consumers. That is to say, it is relatively easier to manipulate or fool consumers in the offline environment, since offline consumers have very limited resources of information, for example their knowledge of the quality of gyms were refined to the area of their neighborhood, and thus consumers were easier to fall into the trap of varying levels of quality for products and services, and their search costs were high if they wanted to expand their knowledge towards the quality. However, on the online environment, their searching costs are dramatically decreased and people can easily know the quality of same or similar products or services on social commerce websites with a click of mouse. This finding gives a highly instructive guidance to online social commerce sellers, which is that the idea that consumers might be easy to be fooled due to the difficult in measuring the quality of products, especially services, is outdated and the medium level discount rates are appropriate to be applied to the products that are related to information transparency.

As to seasonality, people have the common acknowledge that the prices of many products are related to various seasons. Such as the travel package and hotel room reservation, their prices vary a lot in different seasons. Thus, offering a discount on low seasons, such as winter triggers less distrust in consumers than high seasons, such as spring. Therefore, for the advertising e-managers and marketers, medium discount rates are recommended to be offered to products that are considered to be related to seasonality.

Proposition 3: The high level of discount is related to products with high cost of raw material.

The products with high cost of raw material are considered to have relatively fixed prices with less price discounts compared to the majority of products sold on Chinese social commerce websites. That is to say, if high discount rates are applied to these products, online consumers become very alert to the quality of the products since they believe due to the high 
cost of raw material, there is less possibility of high discounts, and if high discounts are provided, they choose not to buy the products.

The low purchase intentions of these products give a very informative practical implication that high discount rates are not recommended to be applied due to the special characteristics of these products. To be specific, people's distrust increasing point is very low compared to the majority of the research subjects and on the actual online social commerce websites, these products should be given more focus on the guarantee of the quality, instead of high discount rates in an effort to increase purchase intentions, which is another valuable practical implication for e-marketers.

Limitation and the directions for future research of this research is shown as below. First, it focused on the extreme case of online social commerce, since Chinese online social commerce websites have more fake products than other countries, it may be problematic to generalize the research propositions to other social commerce markets in other countries. Therefore, in order to increase the external validity and objective of this research, the propositions should be tested in other contexts, such as other countries or other social commerce websites. Second, the internal validity is low since only 20 products were chosen as research subjects in this research, which means with a change of data set, the propositions may change in some extent as well. Therefore, future researches should use empirical data to support the propositions of this research.

\section{References}

[1] Jun Guo and Noor Ismawati Jaafar, “A study on consumers' attitude towards online shopping in China,” International Journal of Business and Social Science, vol.2, no.22, pp. 122-132, December, 2011. Article (CrossRef Link)

[2] Zhao Huang and Morad Benyoucef, "From e-commerce to social commerce: a close look at design features,” Electronic Commerce Research and Applications, vol. 12, no. 4, pp. 246-259, July, 2013. Article (CrossRef Link)

[3] Mihyun Chung and Jaehyoun Kim, "The Internet information and technology research directions based on the fourth industrial revolution," KSII Transactions on Internet \& Information Systems, vol.10, no.3, pp. 1311-1320, March, 2016. Article (CrossRef Link)

[4] Cheol Park and Thae Min Lee, "Information direction, website reputation and eWOM effect: a moderating role of product type,” Journal of Business research, vol. 62, no. 1, pp. 61-67, January, 2009. Article (CrossRef Link)

[5] Xiao Liu and Kwok Kee Wei, "An empirical study of product differences in consumers' e-commerce adoption behavior,” Electronic Commerce Research and Applications, vol. 2, no. 3, pp: 229-239, Autumn, 2003. Article (CrossRef Link)

[6] Kyu Tae Kwak, Youngjoon Cheon, and Bong Gyou Lee, "The sustainability of Korean management in global market: competitive strategy and performance in Korean Ict industry,” KSII Transactions on Internet \& Information Systems, vol.10, no.3, pp. 1344-1361, March, 2016. Article (CrossRef Link)

[7] Feifei Fan, “e-commerce set to grow 15\% by 2020,” available at Article (CrossRef Link)

[8] Kantar, “China Singles Day (Double 11) consumer report 2017 - hottest physical goods are apparel, shoes and food," available at Article (CrossRef Link)

[9] Sanghyun Kim and Hyunsun Park, "Effects of various characteristics of social commerce (s-commerce) on consumers' trust and trust performance,” International Journal of Information Management, vol.33, no.2, pp. 318-32, April, 2013. Article (CrossRef Link)

[10] L. Cecere, "Pioneers on the move: rise of social commerce," available at Article (CrossRef Link)

[11] Crain's Chicago Business, “Groupon co-founders sound off on social commerce,” available at Article (CrossRef Link) 
[12] Paul Marsden, Social commerce: monetizing social media, Syzygy Group, London, 2010.

[13] Ting-Peng Liang and Efraim Turban, "Introduction to the special issue social commerce: a research framework for social commerce,” International Journal of electronic commerce, vol. 16, no. 2, pp. 5-14, December, 2014. Article (CrossRef Link)

[14] Zhao Huang and Morad Benyoucef, "From e-commerce to social commerce: a close look at design features,” Electronic Commerce Research and Applications, vol. 12, no. 4, pp. 246-259, July, 2013. Article (CrossRef Link)

[15] Geng Zhou, Kaiquan Xu, and Stephen SY Liao, "Do starting and ending effects in fixed-price group-buying differ?” Electronic Commerce Research and Applications, vol. 12, no. 2, pp. 78-89, April, 2013. Article (CrossRef Link)

[16] Lina Zhou, Ping Zhang, and Hans-Dieter Zimmermann, "Social commerce research: an integrated view,” Electronic commerce research and applications, vol. 12, no. 2, pp. 61-68, April, 2013. $\underline{\text { Article (CrossRef Link) }}$

[17] Gaurav Bansal and Lijun Chen, "If they trust our e-commerce site, will they trust our social commerce site too? Differentiating the trust in e-commerce and s-commerce: the moderating role of privacy and security concerns," in Proc. of Proceedings of the MWAIS, pp.1-6, May 20-21, 2011. Article (CrossRef Link)

[18] Sirkka L. Jarvenpaa, Noam Tractinsky, and Lauri Saarinen, "Consumer trust in an internet store: a cross -Joutturcal ofalidatinomiter

WhedFatedo.Cammunication, pp.10-20, December, 1999. Article (CrossRef Link)

[19] Invesp, "How social media influences purchase decisions-statistics and trends," available at Article (CrossRef Link).

[20] Sanghyun Kim and Hyunsun Park, "Effects of various characteristics of social commerce (s-commerce) on consumers' trust and trust performance,” International Journal of Information Management, vol.33, no. 2, pp. 318-32, April, 2013. Article (CrossRef Link)

[21] Patricia M. Doney and Joseph P. Cannon, “Trust in buyer-seller relationships,” Journal of Marketing, vol. 61, no.2, pp. 35-51, April, 1997. Article (CrossRef Link)

[22] JungKun Park, Frances Gunn, and Sang-Lin Han, "Multidimensional trust building in E-retailing: cross-cultural differences in trust formation and implications for perceived risk," Journal of Retailing and Consumer Services, vol. 19, no. 3, pp. 304-312, May, 2012. Article (CrossRef Link)

[23] Jingting Shao and Ralf Müller, “The development of constructs of program context and program success: a qualitative study,” International Journal of Project Management, vol. 29, no. 8, pp. 947-959, December, 2011. Article (CrossRef Link)

[24] Jingting Shao and Ralf Müller, "The development of constructs of program context and program success: a qualitative study,” International Journal of Project Management, vol. 29, no. 8, pp. 947-59, December, 2011. Article (CrossRef Link)

[25] Matthew B. Miles and A. Michael Huberman, Qualitative Data Analysis: An Expanded Sourcebook, 2nd Edition, Sage, London, 1994.

[26] Barney G. Glaser and Anselin L. Strauss, Discovery of grounded theory: strategies for qualitative research, Routledge, New York, 2017.

\section{Appendix}

\section{Appendix 1: Interview Guide}

Introduction:

I want to thank you for taking time to meet me today. My name is Lin Li from KyungeHee University, I would like to talk to you about consumers' distrust issue in social commerce websites. Specifically, when your distrust level towards certain products start to increase and what is your reasons. The interview should take around half an hour and I will also take notes during the interview and the contents will be tape recorded for our data analysis. All responses will be kept confidential and your interview response will only be used for research purpose. 
Are there any questions about what I have just explained?

Are you willing to participate in this interview?

Interviewee

Date

Questions:

1. Could you first tell me about some of your personal information, such as your age, educational level, approximate monthly income and the frequency of browsing social commerce website per month?

2. In social commerce websites in general, could you tell me your distrust increasing point towards the quality for the following products?

(For example, when the restaurant coupon has a discount rate of $70 \%$, you start to have distrust, then please tell me the number of $70 \%$.)

\begin{tabular}{|c|c|c|c|}
\hline 1 & 5 & $\begin{array}{l}\text { A pack of A4 paper ( } 500 \\
\text { pieces). } \\
\text { Original price: } \$ 6.9 \text { ( } ¥ 45 \text { ) }\end{array}$ & $\begin{array}{l}\text { At_ }(\%) \text { discount rate, you start to } \\
\text { have distrust towards the quality of } \\
\text { the product? }\end{array}$ \\
\hline 2 & & $\begin{array}{l}\text { Durian (2-3kg). } \\
\text { Original price: } \$ 15 \text { (¥98) }\end{array}$ & $\begin{array}{l}\text { At } \quad(\%) \text { discount rate, you start to } \\
\text { have distrust towards the quality of } \\
\text { the product? }\end{array}$ \\
\hline 3 & & $\begin{array}{l}\text { Staples (quantity:1000). } \\
\text { Original price: } \$ 1.5(¥ 10)\end{array}$ & $\begin{array}{l}\text { At }(\%) \text { discount rate, you start to } \\
\text { have distrust towards the quality of } \\
\text { the product? }\end{array}$ \\
\hline 4 & & $\begin{array}{l}\text { Organic blueberry } 2 \text { boxes } \\
\text { (about } 125 g / \text { box). } \\
\text { Original price: } \$ 12.3 \text { ( } ¥ 80 \text { ) }\end{array}$ & $\begin{array}{l}\text { At_ }(\%) \text { discount rate, you start to } \\
\text { have distrust towards the quality of } \\
\text { the product? }\end{array}$ \\
\hline 5 & & $\begin{array}{l}\text { Gasoline } 30 \text { litter } \\
\text { (\$0.85=¥5.54/litter). } \\
\text { Original price: } \$ 25.6 \text { (¥166.2) }\end{array}$ & $\begin{array}{l}\text { At_ }(\%) \text { discount rate, you start to } \\
\text { have distrust towards the quality of } \\
\text { the product? }\end{array}$ \\
\hline 6 & & $\begin{array}{l}\text { Filet Steak } 150 \mathrm{~g} \times 4+\text { Sirloin } \\
\text { Steak 150g×2 } \\
\text { Original price: } \$ 24.6(¥ 160)\end{array}$ & $\begin{array}{l}\text { At } \quad(\%) \text { discount rate, you start to } \\
\text { have distrust towards the quality of } \\
\text { the product? }\end{array}$ \\
\hline
\end{tabular}




\begin{tabular}{|c|c|c|c|}
\hline 7 & $3 y=$ & $\begin{array}{l}\text { Travel to Seoul 5days \& } 4 \\
\text { nights’ easy package } \\
\text { Original price: \$308 (¥1999) }\end{array}$ & $\begin{array}{l}\text { At_ } \quad(\%) \text { discount rate, you start to } \\
\text { have distrust towards the quality of } \\
\text { the product? }\end{array}$ \\
\hline 8 & & $\begin{array}{l}\text { Modern TV stand } \\
\text { Original price: \$204.8 (¥1329) }\end{array}$ & $\begin{array}{l}\text { At } \quad(\%) \text { discount rate, you start to } \\
\text { have distrust towards the quality of } \\
\text { the product? }\end{array}$ \\
\hline 9 & & $\begin{array}{l}\text { Franchised buffet lunch/dinner } \\
\text { Original price: \$26 (¥169) }\end{array}$ & $\begin{array}{l}\text { At_ }(\%) \text { discount rate, you start to } \\
\text { have distrust towards the quality of } \\
\text { the product? }\end{array}$ \\
\hline 10 & & $\begin{array}{l}\text { Movie ticket } \\
\text { Original price: } \$ 12.3 \text { (¥80) }\end{array}$ & $\begin{array}{l}\text { At } \quad(\%) \text { discount rate, you start to } \\
\text { have distrust towards the quality of } \\
\text { the product? }\end{array}$ \\
\hline 11 & & $\begin{array}{l}\text { Car washing service } \\
\text { Original price: } \$ 5.39 \text { (¥35) }\end{array}$ & $\begin{array}{l}\text { At_ }(\%) \text { discount rate, you start to } \\
\text { have distrust towards the quality of } \\
\text { the product? }\end{array}$ \\
\hline 12 & & $\begin{array}{l}\text { Investment gold bar (2g) } \\
\text { Original price: } \$ 84.6 \text { ( } ¥ 549 \text { ) }\end{array}$ & $\begin{array}{l}\text { At_ }(\%) \text { discount rate, you start to } \\
\text { have distrust towards the quality of } \\
\text { the product? }\end{array}$ \\
\hline 13 & & $\begin{array}{l}\text { Yoga mattress } \\
\text { Original price: \$15.8 (¥103) }\end{array}$ & $\begin{array}{l}\text { At_ }(\%) \text { discount rate, you start to } \\
\text { have distrust towards the quality of } \\
\text { the product? }\end{array}$ \\
\hline 14 & & $\begin{array}{l}\text { Gym exercise coupon } \\
\text { (5 times) } \\
\text { Original price: } \$ 30.8 \text { (¥200) }\end{array}$ & $\begin{array}{l}\text { At } \quad(\%) \text { discount rate, you start to } \\
\text { have distrust towards the quality of } \\
\text { the product? }\end{array}$ \\
\hline 15 & & $\begin{array}{l}\text { Franchised business hotel } \\
\text { standard room } \\
\text { Original price: \$26 (¥169) }\end{array}$ & $\begin{array}{l}\text { At_ }(\%) \text { discount rate, you start to } \\
\text { have distrust towards the quality of } \\
\text { the product? }\end{array}$ \\
\hline 16 & & $\begin{array}{l}\text { Spring fashion white shoes } \\
\text { Original price: } \$ 56.8 \text { ( } ¥ 369 \text { ) }\end{array}$ & $\begin{array}{l}\text { At_ }(\%) \text { discount rate, you start to } \\
\text { have distrust towards the quality of } \\
\text { the product? }\end{array}$ \\
\hline
\end{tabular}




\begin{tabular}{|l|l|l|l|}
\hline 17 & $\begin{array}{l}\text { Strawberry picking experience } \\
\text { Original price: \$30 (¥200) }\end{array}$ & $\begin{array}{l}\text { At_ (\%) discount rate, you start to } \\
\text { have distrust towards the quality of } \\
\text { the product? }\end{array}$ \\
\hline 19 & $\begin{array}{l}\text { Ice-cream } \\
\text { Original price: \$4.6 (¥30) }\end{array}$ & $\begin{array}{l}\text { At_ (\%) discount rate, you start to } \\
\text { have distrust towards the quality of } \\
\text { the product? }\end{array}$ \\
\hline 20 & $\begin{array}{l}\text { Oricture taking } \\
\text { Original price: \$108 (¥699) }\end{array}$ & $\begin{array}{l}\text { At (\%) discount rate, you start to } \\
\text { have distrust towards the quality of } \\
\text { the product? }\end{array}$ \\
\hline
\end{tabular}

3. Could you share with me the reasons? Why do you perceive each item differently? Are there any reasons been listed as below? Or do you have some other reasons?

\begin{tabular}{|c|c|}
\hline \multicolumn{2}{|c|}{ Possible reasons for different distrust level among 20 products } \\
\hline$\square 1$. Based on my past buying experience & $\begin{array}{l}\square 9 \text {. The product is considered identical and } \\
\text { easily to be substituted }\end{array}$ \\
\hline$\square$ 2.Based on other people’s recommendations & $\begin{array}{l}\square 10 \text {. The product is related to personal } \\
\text { important interests like health or safety }\end{array}$ \\
\hline $\begin{array}{l}\square 3 . \text { Based on news or other sources of } \\
\text { information }\end{array}$ & $\begin{array}{l}\square 11 \text {. The product usually has heavy discount } \\
\text { in social commerce websites }\end{array}$ \\
\hline $\begin{array}{l}\square 4 \text {. I have a higher expectation on the quality } \\
\text { of the product }\end{array}$ & $\begin{array}{l}\square 12 \text {. The product usually has high discount } \\
\text { on other channels, such as membership } \\
\text { groups }\end{array}$ \\
\hline$\square$ 5. My personal preference and interest & $\begin{array}{l}\square 13 \text {. The product is easily to tell the quality } \\
\text { without any expertise }\end{array}$ \\
\hline $\begin{array}{l}\square 6 \text {. The influence of advertisements or } \\
\text { fashion trend }\end{array}$ & $\square 14$. The brand effect \\
\hline$\square 7$. The original price of the products & $\begin{array}{l}\square 15 \text {. The product quality is highly influenced } \\
\text { by different seasons }\end{array}$ \\
\hline $\begin{array}{l}\square 8 \text {. The product is very easy to go bad and the } \\
\text { quality is not guaranteed }\end{array}$ & $\begin{array}{l}\square 16 \text {. The product is mostly bought on real } \\
\text { stores instead of buying online }\end{array}$ \\
\hline
\end{tabular}

\section{Closing:}

Is there anything more you would like to add?

I will analyze the data from the interview within one month, and I would be honored to send you back the analysis result. 

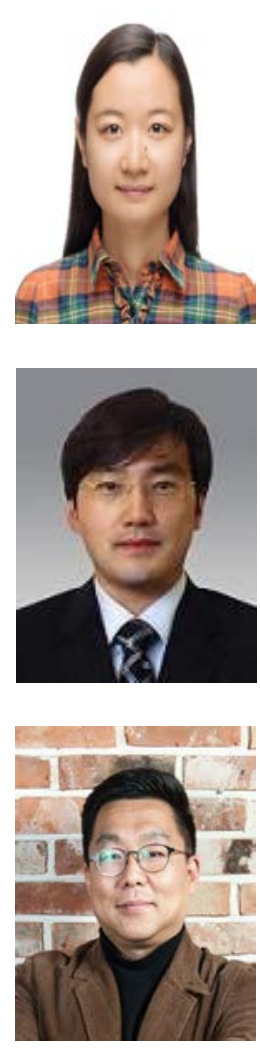

Lin Li is a Ph.D. candidate in the School of Management at Kyung Hee University, Korea. She received her master degree in International Business from Ajou University, Korea. Her research interests include smart tourism, online communities, and e-business strategies.

Cheul Rhee is an associate professor of e-business department at Ajou University in Korea. He has research interests in e-learning, knowledge management, virtual communities, enterprise systems and e-business strategies. He has published papers in journals such as Communications of the ACM, Journal of Electronic Commerce in Organizations, Online Information Review, Asia Pacific Journal of Information Systems, and others.

Junghoon Moon is working for Food Biz Lab. in Seoul National University. His research interests include information management for food industry and food marketing strategies. His recent publications include Decision Support Systems, International Journal of Electronic Commerce, Information \& Management, International Journal of Hospitality Management, Food \& Nutrition Research, and Sustainability. 